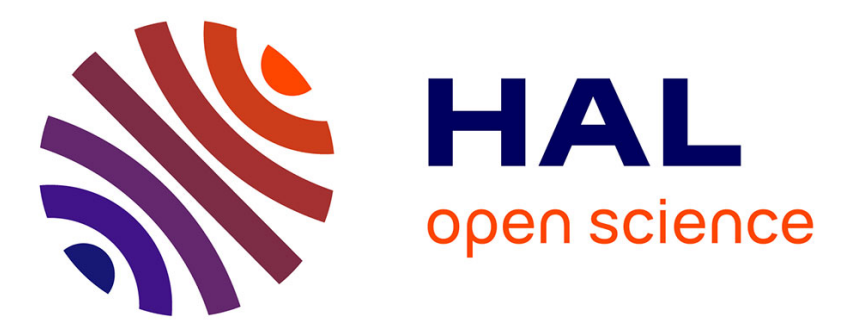

\title{
Long-term consequences of recurrent sports concussion
} Philippe Decq, Nathalie Gault, Mathias Balndeau, Tristan Kerdraon, Miassa Berkal, Amine El Helou, Bernard Dusfour, Jean-Claude Peyrin

\section{To cite this version:}

Philippe Decq, Nathalie Gault, Mathias Balndeau, Tristan Kerdraon, Miassa Berkal, et al.. Longterm consequences of recurrent sports concussion. Acta Neurochirurgica, 2015, 158 (2), pp.289-300. 10.1007/s00701-015-2681-4 . hal-02568459

\section{HAL Id: hal-02568459 \\ https://hal.science/hal-02568459}

Submitted on 9 May 2020

HAL is a multi-disciplinary open access archive for the deposit and dissemination of scientific research documents, whether they are published or not. The documents may come from teaching and research institutions in France or abroad, or from public or private research centers.
L'archive ouverte pluridisciplinaire HAL, est destinée au dépôt et à la diffusion de documents scientifiques de niveau recherche, publiés ou non, émanant des établissements d'enseignement et de recherche français ou étrangers, des laboratoires publics ou privés. 


\title{
Long-term consequences of recurrent sports concussion
}

\author{
Philippe Decq ${ }^{1,3,7}$ - Nathalie Gault ${ }^{2}$ - Mathias Blandeau ${ }^{1,3}$ - Tristan Kerdraon ${ }^{1,3}$. \\ Miassa Berkal $^{1,3} \cdot$ Amine ElHelou $^{4} \cdot$ Bernard Dusfour $^{5} \cdot$ Jean-Claude Peyrin $^{6}$
}

\begin{abstract}
Background Recurrent concussions are suspected to promote the development of long-term neurological disorders. The study was designed to assess the prevalence of major depressive disorder, mild cognitive disorders and headache in a population of retired high-level sportsmen and rugby players and to study the link between scores evaluating these disorders and the number of reported concussions (RCs).

Methods A total of 239 retired rugby players (RRPs) and 138 other retired sportsmen (ORSs) who had reached the French national or international championship level between 1985 and 1990 filled in a self-administered questionnaire describing their sociodemographic data, comorbidities and reported history of RC. A phone interview was then conducted using validated questionnaires for the detection of major depressive disorder (PHQ-9), mild cognitive disorders (F-TICS-m) and headache (HIT-6).
\end{abstract}

Philippe Decq

philippe.decq@aphp.fr

1 Georges Charpak Human Biomecanics Institute, Arts et Métiers ParisTech, Paris, France

2 Assistance Publique Hôpitaux de Paris, Epidemiology and Clinical Research Department, Beaujon Hospital, Clichy, France

3 Assistance Publique Hôpitaux de Paris, Department of Neurosurgery, Beaujon Hospital, Clichy, France

4 Institut du Cerveau et de la Moelle Épinière, Paris, France

5 Ligue Nationale de Rugby, Paris, France

6 Fédération Française de Rugby, Marcoussis, France

7 René Diderot Paris 7 Medical University, Paris, France
Results RRPs reported a higher number of RCs than ORSs $(p<0.001)$. A higher rate of major depressive disorder (PHQ9 score $>9$ ) was observed among RRPs compared to ORSs $(9 \%$ versus $6 \%)(p=0.04)$, and the PHQ- 9 score increased with the number of RCs regardless of the type of sport $(p=0.026)$. A higher rate of mild cognitive disorders (TICS$\mathrm{m}$ score $\leq 30)$ was observed in RRPs compared to ORSs $(57 \%$ versus $40 \%, p=0.005$ ), but no association was found with the number of RC. The HIT- 6 score increased with the number of $\mathrm{RCs}(p=0.019)$ Conclusions More than 20 years after the end of their career, RRPs present higher rates of depression and lower F-TICS-m scores in favor of mild cognitive impairment compared with ORSs. PHQ-9 and HIT-6 scores were significantly associated with the number of RCs.

Keywords Concussion · Rugby · Depression · Cognitive disorder $\cdot$ Headache

\section{Introduction}

According to the American Congress of Rehabilitation Medicine, mild traumatic brain injury is defined as " $a$ traumatically-induced physiologic disruption of brain function including: any period of loss of consciousness $<30 \mathrm{~min}$; any loss of memory $<24 \mathrm{~h}$; any alteration in mental state at the time of the accident; and focal neurological deficits that may or may not be transient [1]. The term "concussion" is generally used in the context of sports. The most recent international consensus conference on concussion in sport [28] established a definition of concussion that reflects the complexity of an apparently "benign" phenomenon that can be briefly described as sudden, transient brain dysfunction following a direct or transmitted blow to the head, which remains one of the 
most difficult forms of sports injury to diagnose, evaluate and manage, as no clinical or complementary diagnostic test is currently available to reliably and immediately confirm the diagnosis $[2,25,26,28]$.

The incidence of concussion in sport varies according to the type of sport, but is higher for so-called collision sports, such as American football or ice hockey [8, 14, 21, 35]. The Center for Disease Control and Prevention has estimated that about 135,000 patients with sports concussion attend emergency departments each year in the USA [19]. The incidence of concussion during rugby matches ranges from 4.1 to 8 concussions per 1,000 player-hours $[13,15]$. Only one study has recorded the number of head impacts (linear accelerations $>10 \mathrm{G}$ ) observed during rugby matches and reported a mean of $564 \pm 618$ impacts per player over the season and a mean of $95 \pm 133$ impacts per player per match [16].

Head impacts, some of which are responsible for clinical concussions, therefore appear to be an inevitable aspect of this type of sport without any apparent sequelae, leading these accidents to be generally considered benign. Only 5 to $10 \%$ of players with concussion have persistent symptoms more than 10 days after the event, which usually completely resolve over a period of several weeks [22]. However, the critical issue is to determine whether repeated concussions can be partly or completely responsible for longer term neurological disorders, such as:

- Depressive disorders: Recent studies in a population of retired American football players (mean age: $53.8 \pm 13.4$ years, mean duration of professional career: $6.6 \pm 3.6$ years) have retrospectively revealed a statistical association between the number of reported concussions and frequency of depressive episodes, although the global frequency of depressive disorders reported in this population is comparable to that observed in the general population [9]. Retired sportsmen who report one or two episodes of concussion appear to be exposed to a 1.5 -fold higher risk of depression than sportsmen with no history of concussion. The risk of depression is increased threefold in sportsmen reporting three or more concussions during their career[11].

- Headache: Headache is frequent after concussion and constitutes one of the key symptoms of the diagnosis of post-concussion syndrome $[4,30]$. Chronic posttraumatic headache is defined as secondary headache in the International Classification of Headache Disorders (ICHD-2) [12]. Its incidence is poorly defined, and its pathophysiology and potential link with the development of neurodegenerative disease remain controversial [36].

- Mild cognitive disorder: The same type of retrospective survey conducted among 513 retired American football players showed that $35 \%$ of them presented an SF-36
Mental Component Summary (MCS) score compatible with possible mild cognitive disorder, and the degree of cognitive impairment increased with the number of reported concussions [10], but this group of sportsmen was not compared with a control group.

- Neurodegenerative disease: A history of serious head injury has been identified for many years as a risk factor for the development of neurodegenerative disease, especially in epidemiological studies of Alzheimer's disease [31]. Regarding concussion, a study of causes of death in a population of 3,439 American football players who had played between 1959 and 1988 revealed an excess mortality due to Alzheimer's disease (standardized mortality ratio $\mathrm{SMR}=3.86$ ), amyotrophic lateral sclerosis $(\mathrm{SMR}=4.31)$ and Parkinson's disease (SMR 1.69) compared to the general population [20]. However, it should be stressed that in this study, the overall mortality was very low compared to that of the general population $(\mathrm{SMR}=0.53)$. Finally, chronic post-traumatic encephalopathy (CTE) has been described for a long time in boxers, for the first time by H. Martland in 1928, although the term was published for the first time only in 1947 by Critchley [6]. Recently, a number of clinical cases and autopsy series have been published concerning sports other than boxing, particularly American football, reopening the debate on the causal relationship between CTE and recurrent concussion $[3,29,32,33]$.

In the absence of prospective epidemiological studies able to establish an indirect or direct relationship between recurrent concussion and these disorders, there are many unresolved controversies that need to be considered very cautiously [27]. Although American football is a sport derived from rugby, to our knowledge no studies have yet been published on the possibility of long-term neurological disorders secondary to rugby injuries.

The purpose of this study was to compare a population of retired rugby players with a population of other retired sportsmen in terms of the prevalence of depressive disorders, mild cognitive disorders and headache and to study the link between scores evaluating these disorders and the number of reported concussions.

\section{Material and methods}

\section{Design}

We conducted a cross-sectional study comparing exposure to recurrent concussion in sports and the incidence of depressive disorders, mild cognitive disorders, fluency disorders and headache. 


\section{Study populations}

This study included retired, French mother tongue, high-level sportsmen, aged 45 to 65 years, who had played sports for at least 10 years and had reached the national or international championship level between 1985 and 1990, divided into two groups:

Rugby (exposed) group Composed of retired rugby players who had reached the first division championship level in France between 1985 and 1990: 1,491 rugby players who had played for 24 clubs were identified from game sheets; 1,047 sportsmen (RRPs) were contacted. Finally, 524 were invited by letter to participate, and 239 (response rate: $46 \%$ ) agreed to participate in the study. This group was considered to be exposed to a risk of recurrent concussion.

Other sports (control) group Composed of other retired sportsmen (ORSs) registered on "high-level" lists between 1985 and 1990: 1,164 sportsmen were identified by the French Ministry of Sports. Eighteen of the 41 sports federations to which these sportsmen belonged agreed to participate in the study representing 637 sportsmen; 455 were invited by letter to participate $(71 \%)$, and 138 (response rate: $30 \%$ ) agreed to participate in the study. This group was considered to be exposed to a lower risk of recurrent concussion.

\section{Study procedure}

\section{We conducted a two-phase study}

First, a self-administered questionnaire was sent to the subjects with an invitation to make a telephone appointment for the second step of the study. When the subject agreed to participate, he returned the completed questionnaire indicating sociodemographic and lifestyle data, comorbidities and the history of reported concussion.

Second, a telephone conversation was conducted by an interviewer specifically devoted to this survey, with the use of validated questionnaires to explore depressive disorders (PHQ-9 score) [17, 23], mild cognitive disorders (F-TICS-m score) $[5,18,39]$, fluency disorders (Isaacs Set Test) [37] and headache severity (HIT-6 score) [24, 40].

The PHQ-9 score was further categorized as follows: minimal depressive disorder (PHQ-9: 0 to 4), mild depressive disorder (PHQ-9: 5 to 9), moderate depressive disorder (PHQ-9: 10 to 14), moderately severe depressive disorder (PHQ-9 15 to 19) and severe depressive disorder (PHQ-9: 20 to 27). A PHQ-9 score $>9$ was considered to be compatible with major depressive disorder [17, 41].
A TICS-m score $\leq 30$ was considered to be compatible with mild cognitive disorder [5].

The severity of the headache and its impact on daily life were further categorized as follows: little or no impact on daily life (HIT-6 $\leq 49$ ), some impact on daily life (HIT-6: 50 to 55), substantial impact on daily life (HIT-6: 56 to 59) and severe impact on daily life (HIT-6 $\geq 60$ ) [40]. An HIT-6 score $\geq 50$ was subsequently considered to be compatible with disabling headache.

\section{Ethics}

Subjects provided their consent to participate in the study. The study obtained a positive opinion from the institutional review board (CEERB PARIS NORD no. 14-048) and authorization from the French data protection authorities (CCTIRS no. 13096 and CNIL no. 913132).

\section{Statistical analysis}

Qualitative variables are expressed as the number and percentage. Quantitative variables are expressed as median and interquartile range as well as mean and standard deviation.

Associations between the number of reported concussions and the PHQ-9, TICS-m, HIT-6 and Isaacs scores were studied successively by univariate linear regression models.

Multivariate analyses were then conducted to adjust for the sport group and factors that were associated with the scores in univariate analyses with a p-value $<0.20$ as well as clinically relevant ones. The results are reported in the form of unadjusted and adjusted regression coefficients with their $95 \%$ confidence interval.

Statistical analysis was performed with R software, version 2.12.0 (The R Foundation for Statistical Computing).

\section{Results}

\section{Results of the self-administered questionnaire}

\section{General description of the population}

The study population comprised 377 retired sportsmen whose general characteristics are presented according to sport group in Table 1. The ORSs participated in various disciplines (athletics, badminton, canoeing, horseback riding, rock climbing, fencing, golf, weightlifting, swimming, paragliding, pelota, skiing, squash, table tennis, archery, triathlon, sailing and gliding). One hundred thirty-three $(56 \%)$ of the sportsmen were forwards and 106 (44\%) were backs. 
Table 1 General characteristics of the study population [data are reported as $\mathrm{n}(\%)$ unless otherwise specified]

\begin{tabular}{|c|c|c|c|c|}
\hline & & $\begin{array}{l}\text { Other sports } \\
N=138\end{array}$ & $\begin{array}{l}\text { Rugby } \\
N=239\end{array}$ & p-value \\
\hline \multicolumn{2}{|c|}{ Age (years) median [IQR] } & $52[49-55]$ & $52[49-55.75]$ & 0.952 \\
\hline \multicolumn{2}{|c|}{ BMI $\left(\mathrm{kg} / \mathrm{m}^{2}\right)$ median [IQR] } & $24.35[22.77-26.48]$ & $28.38[26.12-30.86]$ & $<0.001$ \\
\hline \multicolumn{2}{|l|}{ Higher education } & $84(61.76)$ & $121(51.05)$ & 0.045 \\
\hline \multirow[t]{2}{*}{ Occupational status } & $\begin{array}{l}\text { Full-time employment } \\
\text { Retired }\end{array}$ & $\begin{array}{l}122(89.05) \\
6(4.38)\end{array}$ & $\begin{array}{l}204(86.08) \\
18(7.59)\end{array}$ & 0.474 \\
\hline & Other & $9(6.56)$ & $15(6.32)$ & \\
\hline Marital status & $\begin{array}{l}\text { Marital status (married, } \\
\text { civil union, de facto) } \\
\text { Other }\end{array}$ & $115(83.33)$ & $200(83.68)$ & 0.940 \\
\hline \multicolumn{5}{|c|}{ Lifestyle and medical history } \\
\hline Smoking & Current or former smoker & $52(37.68)$ & $82(34.31)$ & 0.510 \\
\hline \multirow[t]{2}{*}{ Alcohol (frequency) } & $\begin{array}{l}0 \text { to } 3 \text { times a month } \\
11 \text { to } 4 \text { times a week }\end{array}$ & $\begin{array}{l}34(24.64) \\
61(44.2)\end{array}$ & $\begin{array}{l}74(30.96) \\
117(48.95)\end{array}$ & 0.047 \\
\hline & Daily or almost daily & $43(31.16)$ & $48(20.08)$ & \\
\hline \multicolumn{2}{|c|}{ Alcohol (intensity) 5 glasses in 1 day } & $93(71.54)$ & $207(88.09)$ & $<0.001$ \\
\hline \multicolumn{2}{|c|}{ Presence of impaired exercise capacity } & $7(5.11)$ & $29(12.18)$ & 0.025 \\
\hline \multicolumn{2}{|c|}{ Reported neurological disease } & $5(3.68 \%)$ & $7(2.93)$ & 0.763 \\
\hline \multicolumn{2}{|c|}{ Reported chronic disease } & $14(10.14)$ & $26(10.88)$ & 0.824 \\
\hline \multicolumn{2}{|c|}{ Reported depressive episodes } & $17(12.32)$ & $30(12.61)$ & 0.936 \\
\hline \multicolumn{2}{|c|}{ Ongoing antidepressant therapy } & $4(2.9)$ & $6(2.51)$ & 0.999 \\
\hline Perceived state of hea & $\begin{array}{l}\text { Poor } \\
\text { Good } \\
\text { Very good } \\
\text { Excellent }\end{array}$ & $\begin{array}{l}2(1.48) \\
42(31.11) \\
66(48.89) \\
25(18.52)\end{array}$ & $\begin{array}{l}9(3.81) \\
117(49.58) \\
87(36.86) \\
23(9.75)\end{array}$ & $<0.001$ \\
\hline \multicolumn{5}{|c|}{ History of reported concussion } \\
\hline \multicolumn{5}{|c|}{ Total number of reported concussions } \\
\hline \multicolumn{2}{|l|}{ Median [IQR] } & $0[0-0]$ & $2[1-3]$ & $<0.001$ \\
\hline \multicolumn{2}{|l|}{ Mean (SD) } & $0.68(1.83)$ & $3.1(5.01)$ & \\
\hline & None & $104(75.91)$ & $54(22.69)$ & $<0.001$ \\
\hline & $\begin{array}{l}1 \text { or } 2 \\
3 \text { or more }\end{array}$ & $\begin{array}{l}21(15.33) \\
12(8.76)\end{array}$ & $\begin{array}{l}90(37.82) \\
94(39.5)\end{array}$ & \\
\hline \multicolumn{5}{|c|}{ Number of reported concussions with loss of consciousness (among subjects who reported at least 1 concussion) } \\
\hline \multicolumn{2}{|l|}{ Median [IQR] } & $1[1-3]$ & $1[0-2]$ & \\
\hline \multicolumn{2}{|l|}{ Mean (SD) } & $1.64(1.39)$ & $1.51(2.68)$ & \\
\hline \multicolumn{5}{|c|}{ Number of reported concussions with loss of memory (among subjects who reported at least 1 concussion) } \\
\hline \multicolumn{2}{|c|}{ Median [IQR] } & $0[0-1]$ & $0[0-1]$ & \\
\hline \multicolumn{2}{|l|}{ Mean (SD) } & $0.76(1.15)$ & $0.87(1.33)$ & \\
\hline
\end{tabular}

Morphometric data show that RRPs had a significantly higher BMI than other retired sportsmen

\section{Lifestyle and medical history}

Daily alcohol consumption was reported more frequently by other retired sportsmen than RRPs (31\% versus $20 \%$ ), but more RRPs reported heavy drinking ( 5 glasses a day) than ORSs ( $88 \%$ versus $71 \%$ ). RRPs more frequently reported impaired exercise capacity than ORSs $(12 \%$ versus $5 \%)$ and a poorer perceived state of health $(9 \%$ reported an excellent state of health versus $18 \%$ ).

\section{History of reported concussion}

RRPs reported significantly more concussions than other retired sportsmen. The severity of reported concussions was comparable between the two groups in terms of loss of consciousness and loss of memory. Finally, 18\% of RRPs and 
$12 \%$ of ORSs reported concussions occurring in a context other than sports.

\section{Results of the telephone survey}

\section{Factors associated with the PHQ-9 score}

The distribution of the PHQ-9 score is reported in Table 2 and Figs. 1 and 2.

We showed that the median PHQ-9 score was higher in RRPs than other retired sportsmen, and a higher proportion of RRPs reported major depressive disorders (PHQ-9 score $>9)$ than ORSs $(p=0.04)$.

\section{Concussions and PHQ-9 score}

The PHQ-9 score increased with the number of reported concussions regardless of the type of sport performed (Table 3, Fig. 3).

This trend was found to be significant after adjustment in multivariate analysis. History of depressive episodes and perceived state of health were factors independently associated with the PHQ-9 score: subjects with a history of depressive episodes reported higher PHQ-9 scores than those without a history of depressive episodes; similarly, subjects with a less favorable perceived state of health reported higher PHQ-9 scores than others (Table 4).
Table 2 Neuropsychological characteristics of the population [data are reported as n (\%) unless otherwise specified]

\begin{tabular}{|c|c|c|c|}
\hline & $\begin{array}{l}\text { Other sports } \\
N=138\end{array}$ & $\begin{array}{l}\text { Rugby } \\
N=239\end{array}$ & p-value \\
\hline \multicolumn{4}{|l|}{ PHQ-9 score } \\
\hline Median [IQR] & $2[0-4]$ & $3[1-5]$ & \multirow[t]{7}{*}{0.002} \\
\hline Mean (SD) & $2.81(3.23)$ & $3.83(3.55)$ & \\
\hline Minimal depressive disorder (PHQ-9: 0 to 4 ) & $96(80.67)$ & $149(67.7 \%)$ & \\
\hline Mild depressive disorder (PHQ-9: 5 to 9) & $15(12.61)$ & $50(22.73)$ & \\
\hline Moderate depressive disorder (PHQ-9: 10 to 14 ) & $8(6.72)$ & $19(8.64)$ & \\
\hline Moderately severe depressive disorder (PHQ-9: 15 to 19 ) & $0(0)$ & $2(0.91)$ & \\
\hline Severe depressive disorder (PHQ-9: 20 to 27 ) & $0(0)$ & $0(0)$ & \\
\hline Depressive disorders (PHQ-9>9) & $8(6.72 \%)$ & $21(9.55 \%)$ & 0.375 \\
\hline \multicolumn{4}{|l|}{ TICS-m SCORE } \\
\hline Median [IQR] & $31[29-34]$ & $30[28-32]$ & \multirow[t]{2}{*}{0.007} \\
\hline Mean (SD) & $31.26(3.56)$ & $30.24(3.54)$ & \\
\hline Mild cognitive disorders (TICS-m $\leq 30$ ) & $46(40.35 \%)$ & $116(56.59 \%)$ & 0.005 \\
\hline \multicolumn{4}{|l|}{ Total Isaacs score } \\
\hline \multicolumn{4}{|l|}{ Number of cited words } \\
\hline Median [IQR] & 37 [35-39] & $38[35-39]$ & \multirow[t]{2}{*}{0.6457} \\
\hline Mean (SD) & $36.96(2.87)$ & $36.86(3.2)$ & \\
\hline \multicolumn{4}{|l|}{ Number of repetitions } \\
\hline Median [IQR] & $0[0-0.75]$ & $0[0-1]$ & \multirow[t]{2}{*}{0.8825} \\
\hline Mean (SD) & $0.3(0.48)$ & $0.55(1.8)$ & \\
\hline \multicolumn{4}{|l|}{ Number of errors } \\
\hline Median [IQR] & $2[0.25-2.75]$ & $1[0-2]$ & \multirow[t]{2}{*}{0.2804} \\
\hline Mean (SD) & $1.7(1.42)$ & $1.22(1.23)$ & \\
\hline \multicolumn{4}{|l|}{ HIT-6 score } \\
\hline Median [IQR] & $36[36-40]$ & $38[36-44]$ & \multirow[t]{2}{*}{0.084} \\
\hline Mean (SD) & $40.08(7.07)$ & $41.03(7.16)$ & \\
\hline \multicolumn{4}{|l|}{ Impact of headache } \\
\hline Little or no impact on daily life (HIT-6 $\leq 49)$ & $102(87.18)$ & $185(84.47)$ & \\
\hline Some impact on daily life (HIT-6: 50 to 55 ) & $9(7.69)$ & $20(9.13)$ & \\
\hline Substantial impact on daily life (HIT-6: 56 to 59) & $3(2.56)$ & $8(3.65)$ & \\
\hline Severe impact on daily life (HIT- $6 \geq 60$ ) & $3(2.56)$ & $6(2.74)$ & \\
\hline Disabling headache (HIT-6 $\geq 50)$ & $15(12.82)$ & $34(15.53)$ & 0.503 \\
\hline
\end{tabular}




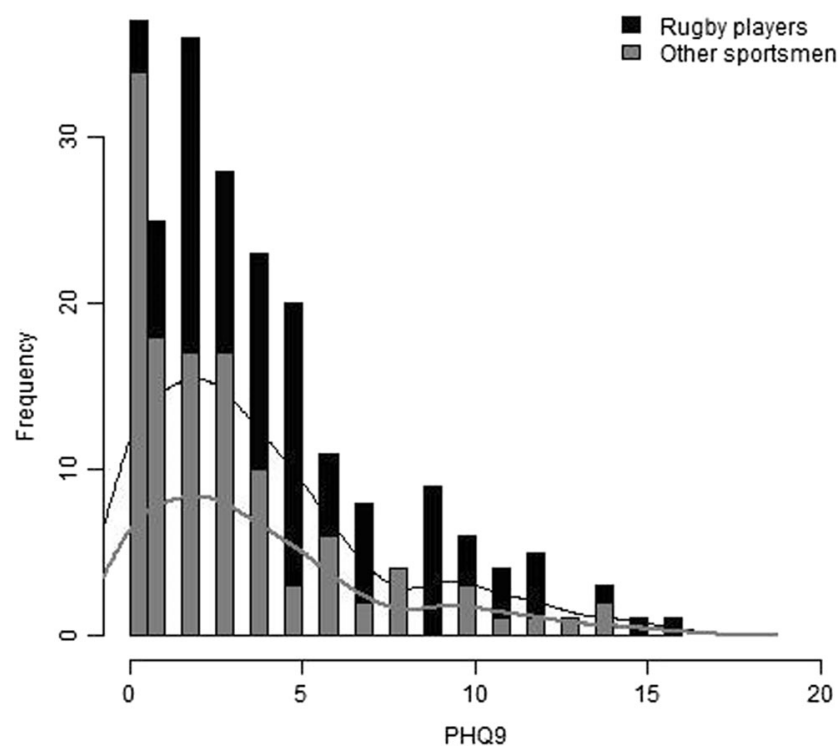

Fig. 1 Distribution of PHQ-9 scores in the two groups of retired sportsmen (the height of the bar represents the number of subjects with the corresponding score)

\section{Factors associated with the TICS-m score}

The distribution of the TICS-m score is reported in Table 2 and in Figs. 4 and 5.

We showed that the median TICS-m score was lower in RRPs than ORSs $(p=0.007)$, and more mild cognitive disorders (TICS-m score $\leq 30$ ) were observed in RRPs compared to ORSs $(p=0.005)$.

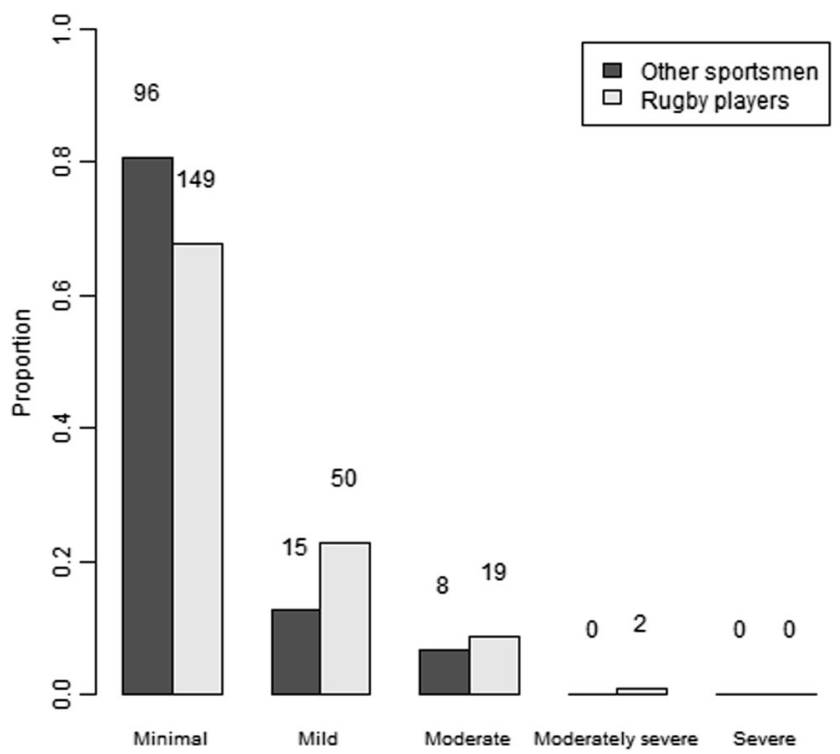

Fig. 2 Distribution of severity of depressive disorders in the two groups of retired sportsmen
Table 3 Distribution of PHQ-9 scores according to the number of reported concussions

\begin{tabular}{lcllll}
\hline \multicolumn{5}{c}{ Number of reported concussions } \\
\hline & None & 1 or 2 & 3 or more & Total \\
Total & Median & $2[1-4]$ & $3[1-6]$ & $3[1-6]$ & $3[1-5]$ \\
$\begin{array}{l}\text { PHQ- } \\
\text { 9 score }\end{array}$ & {$[\mathrm{IQR}]$} & & & & \\
& Mean (SD) & $2.92(3.1)$ & $3.74(3.57)$ & $3.98(3.77)$ & $3.47(3.47)$ \\
\hline
\end{tabular}

\section{Concussion regardless of the type of sport and detection of mild cognitive disorders}

The median TICS-m score seemed to be lower if concussions were reported (Table 5).

After adjustment, smoking and higher education were factors independently associated with a higher TICS-m score, while the sport group and age were factors independently associated with a lower TICS-m score. No association was observed between the TICS-m score and number of reported concussions (Table 6).

\section{Study of verbal fluency disorders}

Overall, no significant difference in verbal fluency was observed between the two groups of retired sportsmen (Table 2). In univariate analysis, neither the number of

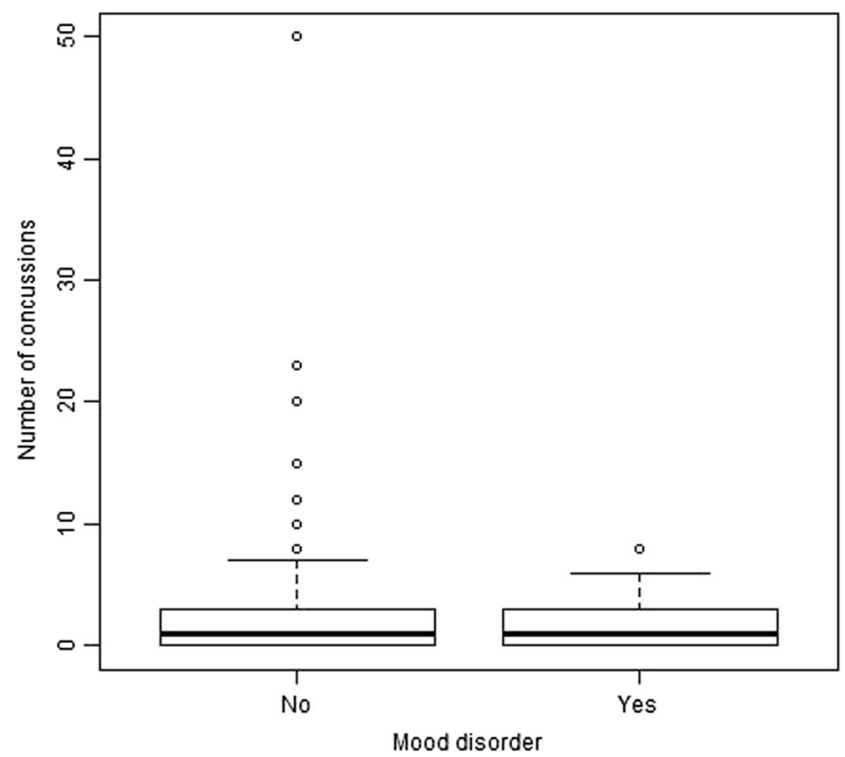

Fig. 3 Boxplot representing the distribution of the number of reported concussions according to the presence of depressive disorders (PHQ-9>9) 
Table 4 Analysis of factors associated with the PHQ-9 score

\begin{tabular}{lllll}
\hline & & Unadjusted estimate & Adjusted estimate & $\mathrm{p}$ \\
\hline Retired rugby players & & $1.02[0.25-1.79]$ & $0.09[-0.98-1.15]$ & 0.875 \\
Number of concussions & 1 or 2 & $0.82[-0.07-1.70]$ & $0.90[-0.17-1.97]$ & 0.097 \\
& 3 or more & $1.06[0.17-1.95]$ & $1.23[0.14-2.32]$ & 0.026 \\
Reported depressive episode & & $2.41[1.28-3.53]$ & $1.86[0.63-3.10]$ & 0.003 \\
Chronic disease & & $1.01[-0.16-2.18]$ & $0.78[-0.68-2.25]$ & 0.292 \\
Impaired exercise capacity & & $2.14[0.96-3.32]$ & $1.90[-0.38-4.18]$ & 0.102 \\
Difficulty climbing stairs & & $3.73[1.04-6.42]$ & $0.99[-2.08-4.06]$ & 0.525 \\
BMI* & & $0.09[-0.00-0.18]$ & $-0.05[-0.17-0.07]$ & 0.430 \\
Perceived state of health & Good & $-2.61[-4.67-0.56]$ & $-2.85[-5.44-0.26]$ & 0.031 \\
& Very good & $-4.42[-6.48--2.37]$ & $-3.74[-6.41-1.07]$ & 0.006 \\
& Excellent & $-3.91[-6.13--1.69]$ & $-3.23[-6.05-0.42]$ & 0.024 \\
\hline
\end{tabular}

*By increments of $1 \mathrm{~kg} / \mathrm{m}^{2}$

NB: Interpretation of estimates: an estimate $>0$ indicates that the factor is associated with a higher PHQ- 9 score; inversely, an estimate $<0$ indicates that the factor is associated with a lower PHQ-9 score reported concussions nor the group of retired sportsmen was associated with a modification of the total Isaacs score.

\section{Factors associated with the HIT-6 score}

The distribution of the HIT-6 score is reported in Table 2 and Figs. 6 and 7.

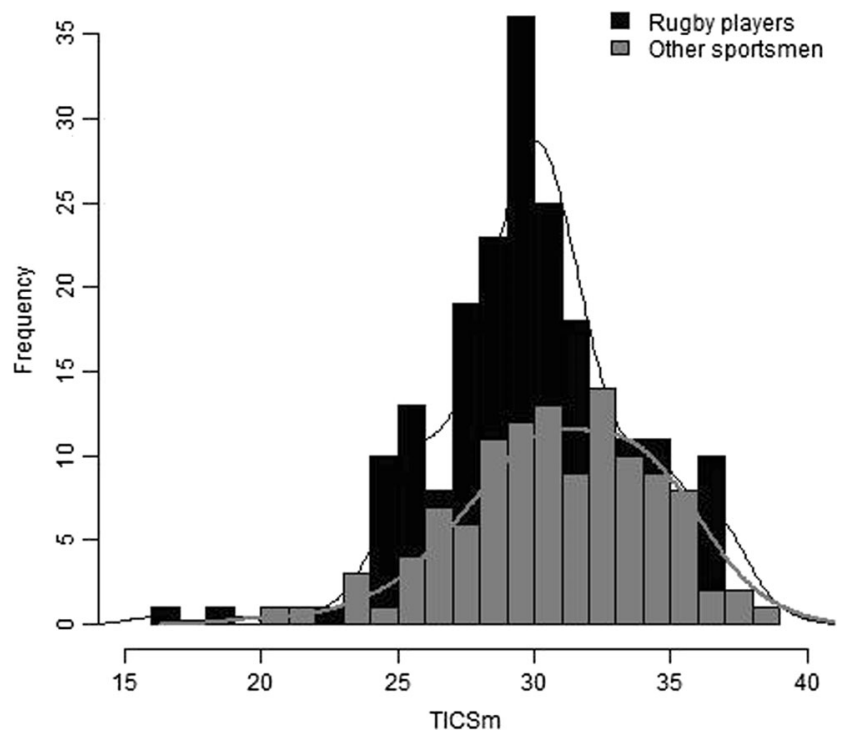

Fig. 4 Distribution of TICS-m scores in the two groups of retired sportsmen (the height of the bar represents the number of subjects with the corresponding score)
The median HIT-6 score was higher in the group of RRPs than in the group of ORSs $(p=0.084)$, with a similar proportion of subjects with disabling headache with an impact on daily life in the two groups (Table 2).

\section{Concussion and the HIT-6 score}

The HIT-6 score increased with the number of reported concussions (Table 7 and Fig. 8).

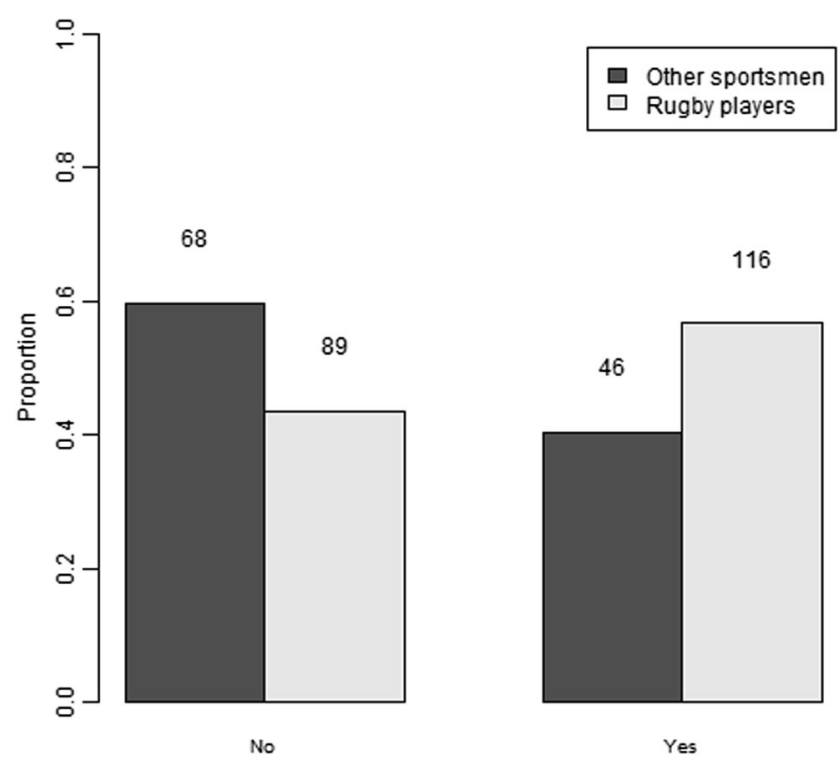

Fig. 5 Distribution of the presence of mild cognitive disorders (TICS$\mathrm{m}<30$ ) in the two groups of retired sportsmen 
Table 5 Distribution of the TICS-m score according to the number of reported concussions

\begin{tabular}{llllll}
\hline \multicolumn{5}{c}{ Number of reported concussions } \\
\hline & None & 1 or 2 & 3 or more & Total \\
Total TICS-m score & Median [IQR] & $31[28.75-33]$ & $30[28-33]$ & $30[29-32]$ & $30[28.5-33]$ \\
& Mean (SD) & $30.76(3.7)$ & $30.39(3.73)$ & $30.62(3.23)$ & $30.61(3.57)$ \\
\hline
\end{tabular}

This trend was found to be significant after adjustment on multivariate analysis (Table 8). A history of depression was also a factor independently associated with a higher HIT-6 score.

\section{Discussion}

This retrospective study conducted in 2014 in a population of retired, top-level sportsmen around the age of 50 years who had played competitive sport between 1985 and 1990 shows that:

RRPs reported more concussions per player and more recurrent concussions than ORSs.

A higher rate of major depressive disorder (defined by a PHQ-9>9) was observed in RRPs compared to ORSs. A statistically significant association was observed between the PHQ-9 score and number of reported concussions.

A higher rate of mild cognitive disorder (defined by a TICS-m score $\leq 30$ ) was observed in RRPs compared to ORSs, but no statistically significant association was observed between the TICS-m score and number of reported concussions.
A statistically significant association was observed between the HIT-6 score used for the detection of chronic headache and the number of reported concussions.

\section{An important recruitment bias}

Finding the names and contact information of subjects who ended their sporting career several decades previously is difficult. Sports club files are often fragmented and not updated. Some clubs may even have disappeared. The most reliable source remains retired player associations, but they only comprise former players who are still actively involved in rugby and the life of their former club. Contact with retired players is based more on word of mouth than reliable databases. A large proportion of players identified on game sheets cannot be contacted because they have changed region or even country or because they are now ill or even dead. Therefore, the study population is composed of players with better scores for the various factors studied inasmuch as they have maintained an effective network of social relations. It could be speculated that any abnormality detected in this population would be underestimated compared to the overall population, but probably not overestimated. This type of bias related to the
Table 6 Analysis of factors associated with the TICS-m score

\begin{tabular}{llll}
\hline & Unadjusted estimate & Adjusted estimate & $\mathrm{P}$ \\
\hline Retired rugby players & $-1.019[-1.834-0.204]$ & $-1.295[-2.503-0.087]$ & 0.036 \\
Number of concussions & & & 0.457 \\
None & 0 & 0 & \\
1 or 2 & $-0.368[-1.316-0.580]$ & $0.153[-1.059-1.364]$ & \\
3 or more & $-0.138[-1.095-0.819]$ & $0.733[-0.533-2.000]$ & \\
Head injury unrelated to sport & $0.773[-0.352-1.899]$ & $0.437[-0.802-1.676]$ & 0.487 \\
Higher education & $1.412[0.627-2.198]$ & $1.241[0.351-2.132]$ & 0.006 \\
Difficulty climbing stairs & $-2.573[-5.488-0.341]$ & $-0.838[-3.785-2.11]$ & 0.576 \\
Current or former smoker & $0.598[-0.214-1.411]$ & $1.072[0.154-1.99]$ & 0.022 \\
Perceived state of health & & & $<0.001$ \\
Very good or Excellent & $-2.555[-5.068-0.041]$ & $-1.789[-4.915-1.338]$ & 0.261 \\
Neurological disease & $-0.905[-2.147-0.338]$ & $0.919[-0.751-2.589]$ & 0.279 \\
Chronic disease & $-0.116[-0.189-0.044]$ & $-0.126[-0.213-0.04]$ & 0.004 \\
Age (by 1-year increments) & $-0.094[-0.193-0.005]$ & $0.08[-0.06-0.22]$ & 0.259 \\
BMI (kg/m ${ }^{2}$ by increments) & & $1.778[0.819-2.736]$ & \\
\hline
\end{tabular}

NB: Interpretation of estimates: an estimate $>0$ indicates that the factor is associated with a higher TICS-m score; inversely, an estimate $<0$ indicates that the factor is associated with a lower TICS-m score. 


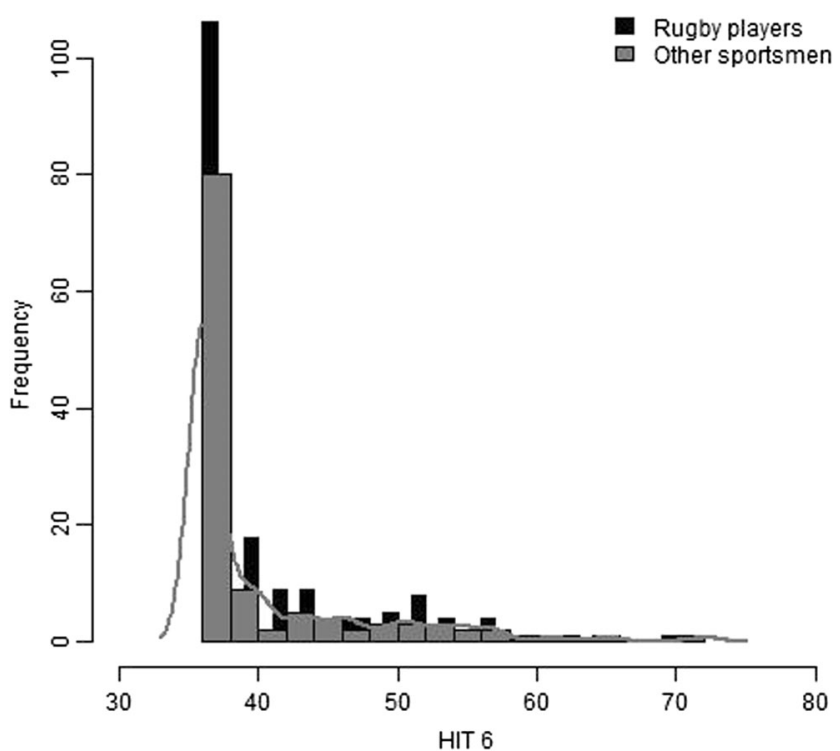

Fig. 6 Distribution of the HIT-6 score in the two groups of retired sportsmen (the height of the bar represents the number of subjects with the corresponding score)

selection of a healthier population has been extensively described in epidemiological studies [34].

\section{Choice of telephone interview}

The recruitment difficulty was compounded by the difficulty of ensuring good quality neurological assessment for subjects living in various regions all over France and still working, allowing them little time to participate in a study that would require global evaluation of their cognition, which could last several hours. It was therefore decided to conduct this

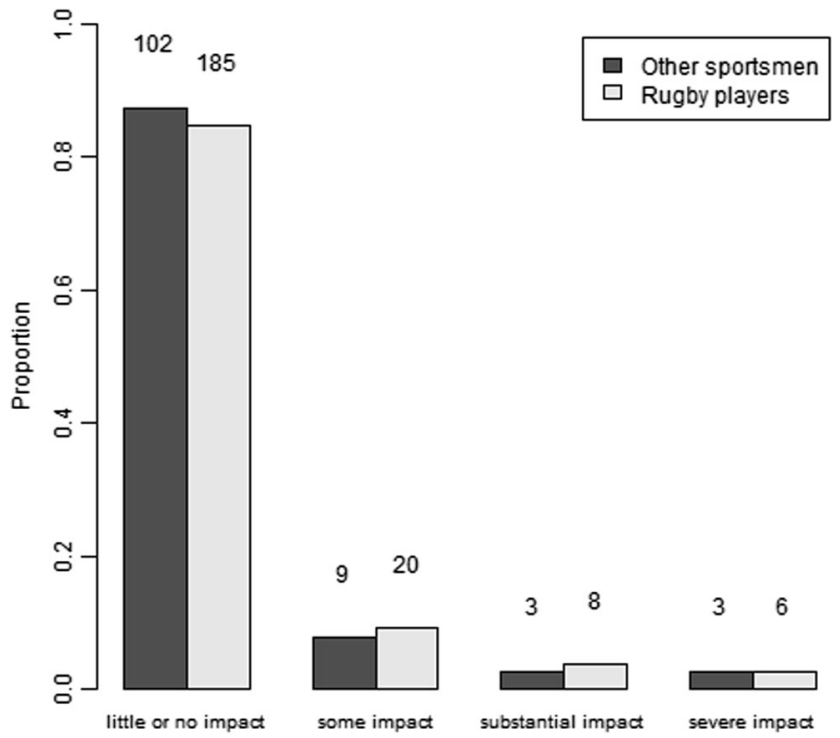

Fig. 7 Distribution of the severity of the impact of headache in the two groups of retired sportsmen
Table 7 Distribution of the HIT-6 score according to the number of reported concussions

\begin{tabular}{|c|c|c|c|c|c|}
\hline & & \multicolumn{4}{|c|}{ Number of reported concussions } \\
\hline & & None & 1 or 2 & 3 or more & Total \\
\hline \multirow[t]{2}{*}{$\begin{array}{l}\text { HIT-6 } \\
\text { score }\end{array}$} & $\begin{array}{l}\text { Median } \\
\text { [IQR] }\end{array}$ & $36[36-40]$ & $38[36-44]$ & $38[36-46]$ & $36[36-43]$ \\
\hline & $\begin{array}{l}\text { Mean } \\
\text { (SD) }\end{array}$ & $\begin{array}{l}39.53 \\
\quad(6.41)\end{array}$ & $\begin{array}{l}41.11 \\
\quad(7.51)\end{array}$ & $\begin{array}{l}41.98 \\
\quad(7.53)\end{array}$ & $\begin{array}{l}40.71 \\
\quad(7.14)\end{array}$ \\
\hline
\end{tabular}

assessment by self-administered questionnaire and telephone interview. A similar methodology was used in the study by Guskiewicz on retired American football players [11]. The scores and scales used during the telephone interview are validated tools for the detection of depressive disorders, mild cognitive disorders and headache in the general population, with a global duration not exceeding $30 \mathrm{~min}$, a duration compatible with the time that these retired players would be likely to devote to the survey.

\section{The declarative nature of concussion: memorization bias}

Another possible bias of the study is related to the declarative nature of concussions. These events were long considered a "normal" part of rugby and have been largely under-evaluated and under-declared even up until very recently [38]. Furthermore, the only events retrospectively identified as concussion were usually those causing loss of consciousness, which represent only $15 \%$ of documented concussions [7]. Finally, these events are often accompanied by amnesia, which does not facilitate recall by the subjects concerned, particularly many

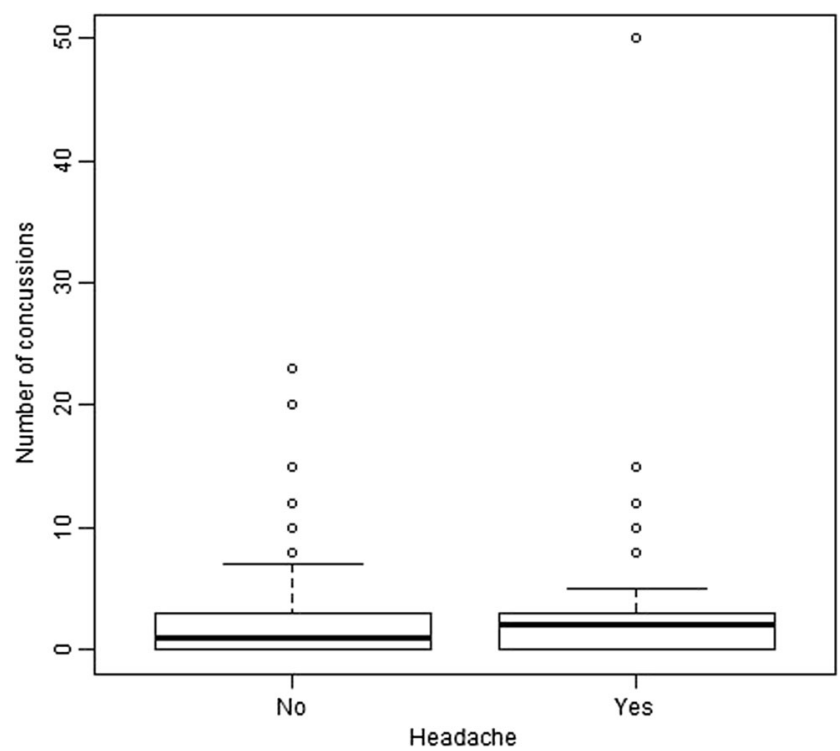

Fig. 8 Boxplot representing the distribution of the number of reported concussions according to the presence of disabling headache 
Table 8 Analysis of factors associated with the HIT-6 score

\begin{tabular}{llll}
\hline & Unadjusted estimate & Adjusted estimate & $\mathrm{P}$ \\
\hline $\begin{array}{l}\text { Retired rugby players } \\
\text { Number of concussions }\end{array}$ & $0.91[-0.70-2.52]$ & $-0.56[-2.48-1.36]$ & 0.567 \\
$\quad$ None & 0 & & \\
1 or 2 & $1.58[-0.26-3.42]$ & $1.86[-0.22-3.94]$ & 0.079 \\
3 or more & $2.45[0.62-4.28]$ & $2.54[0.42-4.66]$ & 0.019 \\
History of depression & $2.65[0.24-5.06]$ & $2.51[0.12-4.91]$ & 0.040 \\
Impaired exercise capacity & $1.80[-0.68-4.27]$ & $1.92[-0.56-4.40]$ & 0.129 \\
Age $*$ & $-0.12[-0.26-0.03]$ & $-0.11[-0.26-0.04]$ & 0.136 \\
\hline
\end{tabular}

*By 1-year increments

NB: Interpretation of estimates: an estimate $>0$ indicates that the factor is associated with a higher HIT- 6 score; inversely, an estimate $<0$ indicates that the factor is associated with a lower HIT-6 score years later. The number of reported concussions in this study is therefore probably largely underestimated.

\section{Other confounding factors}

Other confounding factors were probably not collected. In order to minimize this bias, it was decided to compare RRPs with ORSs with little or no exposure to a risk of recurrent concussion, but who had achieved a comparable level of competitive sports during the same period and who had been submitted to the same environment (diet, smoking, drinking, doping temptation, etc.). It must be remembered that concussions can occur regardless of the sport considered, but that the main characteristic of contact sports is the possibility of repeated concussions, which can also occur in the context of other sports but much less frequently. Together with the type of sport (contact or non-contact sport), recurrent concussion is probably also related to individual high-risk behavior, which is another confounding factor that was not taken into account in the present study.

\section{Conclusion}

This study showed that RRPs reported a significantly greater number of concussions and recurrent concussions than ORSs. Their results on the PHQ-9 score, used to detect depressive disorders, and the TICS-m score, used to detect mild cognitive disorders, were also significantly different. A statistically significant association was observed between the PHQ-9 score and number of reported concussions regardless of the type of sport performed, but no such association was observed for the TICS-m score. Finally, a statistically significant association was also observed between the HIT-6 score and the number of reported concussions. These results confirm some of the results reported in American football players. However, no increased incidence of clinically significant episodes of depression or cognitive decline was observed in this population of retired sportsmen compared to the general population. Due to the numerous biases of this study design, these results need to be confirmed, ideally by means of larger scale prospective studies.

Acknowledgments We thank Timothée Six for help with the data acquisition.

This work was supported by a grant from the Fédération Française de Rugby (FFR) and the Ligue Nationale de Rugby (LNR) and performed under the auspices of the Comité National Olympique et du Sport Français (CNOSF). There are no competing interests.

\section{Compliance with ethical standards}

Funding The Fédération Française de Rugby (FFR) and la Ligue Nationale de Rugby (LNR) provided financial support in the form of research technician funding. The sponsor had no role in the design or conduct of this research.

Conflict of interest All authors certify that they have no affiliations with or involvement in any organization or entity with any financial interest (such as honoraria; educational grants; participation in speakers' bureaus; membership, employment, consultancies, stock ownership, or other equity interest; and expert testimony or patent-licensing arrangements), or non-financial interest (such as personal or professional relationships, affiliations, knowledge or beliefs) in the subject matter or materials discussed in this manuscript. Drs. Jean-Claude Peyrin and Bernard Dusfour are respectively president of the medical committee of the FFR and of the LNR.

Ethical approval All procedures performed in studies involving human participants were in accordance with the ethical standards of the institutional and/or national research committee and with the $1964 \mathrm{Hel}-$ sinki Declaration and its later amendments or comparable ethical standards.

Informed consent Informed consent was obtained from all individual participants included in the study. 


\section{References}

1. ACRM: Mild Traumatic Brain Injury Committee (1993) Definition of mild traumatic brain injury. J Head Trauma Rehabil 8(3):86-87

2. Aubry M, Cantu R, Dvorak J, Graf-Baumann T, Johnston K, Kelly J, Lovell M, McCrory P, Meeuwisse W, Schamasch P, Concussion in Sport Group (2002) Summary and agreement statement of the First International Conference on Concussion in Sport, Vienna 2001. Recommendations for the improvement of safety and health of athletes who may suffer concussive injuries. Clin J Sport Med 12(1):6-11

3. Cantu RC (2007) Chronic traumatic encephalopathy in the National Football League. Neurosurgery 61(2):223-225

4. Carney N, Ghajar J, Jagoda A, Bedrick S, Davis-O Reilly C, du Coudray H, Hack D, Helfand N, Huddleston A, Nettleton T, Riggio S (2014) Concussion guidelines step 1: systematic review of prevalent indicators. Neurosurgery 75(Suppl 1):S3-S15

5. Cook SE, Marsiske M, McCoy KJ (2009) The use of the Modified Telephone Interview for Cognitive Status (TICS-M) in the detection of amnestic mild cognitive impairment. J Geriatr Psychiatry Neurol 22(2):103-109

6. Critchley M (1949) Punch-drunk syndromes: the chronic traumatic encephalopathy of boxers. Hommage à Clovis Vincent. Neurochirurgie, Maloine, Paris

7. Decq P, Chermann J-F, Loiseau H, Pariente J, Touchon J, Mias L, Vidalin H, Lagarrigue J (2011) Professional rugby and head injury (Concussions): Guidelines for their management in France. J de Traumatologie du Sport 28(4):227-242

8. Gessel LM, Fields SK, Collins CL, Dick RW, Comstock RD (2007) Concussions among United States high school and collegiate athletes. J Athl Train 42(4):495-503

9. Gonzalez HM, Tarraf W, Whitfield KE, Vega WA (2010) The epidemiology of major depression and ethnicity in the United States. J Psychiatr Res 44(15):1043-1051

10. Guskiewicz KM, Marshall SW, Bailes J, McCrea M, Cantu RC, Randolph C, Jordan BD (2005) Association between recurrent concussion and late-life cognitive impairment in retired professional football players. Neurosurgery 57(4):719-726

11. Guskiewicz KM, Marshall SW, Bailes J, McCrea M, Harding HP Jr, Matthews A, Mihalik JR, Cantu RC (2007) Recurrent concussion and risk of depression in retired professional football players. Med Sci Sports Exerc 39(6):903-909

12. Headache Classification Committee of the International Headache (2013) The International Classification of Headache Disorders, 3rd edition. Cephalalgia 33(9):629-808

13. Hollis SJ, Stevenson MR, McIntosh AS, Shores EA, Finch CF (2012) Compliance with return-to-play regulations following concussion in Australian schoolboy and community rugby union players. Br J Sports Med 46(10):735-740

14. Hootman JM, Dick R, Agel J (2007) Epidemiology of collegiate injuries for 15 sports: summary and recommendations for injury prevention initiatives. J Athl Train 42(2):311-319

15. Kemp SP, Hudson Z, Brooks JH, Fuller CW (2008) The epidemiology of head injuries in English professional rugby union. Clin $\mathrm{J}$ Sport Med 18(3):227-234

16. King D, Hume PA, Brughelli M, Gissane C (2015) Instrumented mouthguard acceleration analyses for head impacts in amateur rugby union players over a season of matches. Am J Sports Med 43(3): 614-624

17. Kroenke K, Spitzer RL, Williams JB (2001) The PHQ-9: validity of a brief depression severity measure. J Gen Intern Med 16(9):606613

18. Lacoste L, Trivalle C (2009) Adaptation francaise d'un outil d'évaluation par téléphone des troubles mnésiques: le French
Telephone Interview for Cognitive Status Modified F-TICS-m). Neurologie-Psychiatrie-Gériatrie 9(49):17-22

19. Laker SR (2011) Epidemiology of concussion and mild traumatic brain injury. PM R 3(10 Suppl 2):S354-S358

20. Lehman EJ, Hein MJ, Baron SL, Gersic CM (2012) Neurodegenerative causes of death among retired National Football League players. Neurology 79(19):1970-1974

21. Lincoln AE, Caswell SV, Almquist JL, Dunn RE, Norris JB, Hinton RY (2011) Trends in concussion incidence in high school sports: a prospective 11-year study. Am J Sports Med 39(5):958-963

22. Makdissi M, Darby D, Maruff P, Ugoni A, Brukner P, McCrory PR (2010) Natural history of concussion in sport: markers of severity and implications for management. Am J Sports Med 38(3):464-471

23. Martin A, Rief W, Klaiberg A, Braehler E (2006) Validity of the Brief Patient Health Questionnaire Mood Scale (PHQ-9) in the general population. Gen Hosp Psychiatry 28(1):71-77

24. Martin M, Blaisdell B, Kwong JW, Bjorner JB (2004) The ShortForm Headache Impact Test (HIT-6) was psychometrically equivalent in nine languages. J Clin Epidemiol 57(12):1271-1278

25. McCrory P, Johnston K, Meeuwisse W, Aubry M, Cantu R, Dvorak J, Graf-Baumann T, Kelly J, Lovell M, Schamasch P (2005) Summary and agreement statement of the 2nd International Conference on Concussion in Sport, Prague. Br J Sports Med 39(4):196-204

26. McCrory P, Meeuwisse W, Johnston K, Dvorak J, Aubry M, Molloy M, Cantu R (2009) Consensus statement on concussion in sport - the Third International Conference on Concussion in Sport held in Zurich, November 2008. Phys Sportsmed 37(2): 141-159

27. McCrory P, Meeuwisse WH, Kutcher JS, Jordan BD, Gardner A (2013) What is the evidence for chronic concussion-related changes in retired athletes: behavioural, pathological and clinical outcomes? Br J Sports Med 47(5):327-330

28. McCrory P, Meeuwisse WH, Aubry M, Cantu B, Dvorák J, Echemendia RJ, Engebretsen L, Johnston K, Kutcher JS, Raftery M, Sills A, Benson BW, Davis GA, Ellenbogen RG, Guskiewicz K, Herring SA, Iverson GL, Jordan BD, Kissick J, McCrea M, McIntosh AS, Maddocks D, Makdissi M, Purcell L, Putukian M, Schneider K, Tator CH, Turner M (2013) Consensus statement on concussion in sport: the 4th International Conference on Concussion in Sport held in Zurich, November 2012. Br J Sports Med 47(5):250-258

29. McKee AC, Gavett BE, Stern RA, Nowinski CJ, Cantu RC, Kowall NW, Perl DP, Hedley-Whyte ET, Price B, Sullivan C, Morin P, Lee HS, Kubilus CA, Daneshvar DH, Wulff M, Budson AE (2010) TDP-43 proteinopathy and motor neuron disease in chronic traumatic encephalopathy. J Neuropathol Exp Neurol 69(9):918-929

30. Merritt VC, Rabinowitz AR, Arnett PA (2015) Injury-related predictors of symptom severity following sports-related concussion. J Clin Exp Neuropsychol 37(3):265-275

31. Mortimer JA, van Duijn CM, Chandra V, Fratiglioni L, Graves AB, Heyman A, Jorm AF, Kokmen E, Kondo K, Rocca WA (1991) Head trauma as a risk factor for Alzheimer's disease: a collaborative re-analysis of case-control studies. EURODEM Risk Factors Research Group. Int J Epidemiol 20(Supp1 2):S28-S35

32. Omalu BI, DeKosky ST, Minster RL, Kamboh MI, Hamilton RL, Wecht CH (2005) Chronic traumatic encephalopathy in a National Football League player. Neurosurgery 57(1):128-134

33. Omalu BI, DeKosky ST, Hamilton RL, Hamilton RL, Minster RL, Kamboh MI, Shakir AM, Wecht CH (2006) Chronic traumatic encephalopathy in a national football league player: part II. Neurosurgery 59(5):1086-1092

34. Rothman KJ, Greenland S, Lash TL (2008) Modern Epidemiology. Wolters Kluwer Health/Lippincott Williams \& Wilkins

35. Schulz MR, Marshall SW, Mueller FO, Yang J, Weaver NL, Kalsbeek WD, Bowling JM (2004) Incidence and risk factors for 
concussion in high school athletes, North Carolina, 1996-1999. Am J Epidemiol 160(10):937-944

36. Seifert TD (2013) Sports concussion and associated post-traumatic headache. Headache 53(5):726-736

37. Thomas Antérion $\mathrm{C}$, Honoré $\mathrm{S}$, Cougny H, Grosmaitre C, Laurent B (2001) Apport de l'épreuve d'évocation lexicale du Set Test dans le dépistage de la maladie d'Alzheimer. Rev Neurol (Paris) 157(11): 1377-1382

38. Torres DM, Galetta KM, Phillips HW, Dziemianowicz EM, Wilson JA, Dorman ES, Laudano E, Galetta SL, Balcer LJ (2013) Sportsrelated concussion: Anonymous survey of a collegiate cohort. Neurol Clin Pract 3(4):279-287
39. Vercambre MN, Cuvelier H, Gayon YA, Hardy-Léger I, Berr C, Trivalle C, Boutron-Ruault MC, Clavel-Chapelon F (2010) Validation study of a French version of the modified telephone interview for cognitive status (F-TICS-m) in elderly women. Int J Geriatr Psychiatry 25(11):1142-1149

40. Yang M, Rendas-Baum R, Varon SF, Kosinski M (2011) Validation of the Headache Impact Test (HIT-6) across episodic and chronic migraine. Cephalalgia 31(3):357-367

41. Zuithoff NP, Vergouwe Y, King M, Nazareth I, van Wezep MJ, Moons KG, Geerlings MI (2010) The Patient Health Questionnaire-9 for detection of major depressive disorder in primary care: consequences of current thresholds in a crosssectional study. BMC Fam Pract 11:98 